\title{
Quantification, Persistence, and Status of Dodine Resistance in New York and Michigan Orchard Populations of Venturia inaequalis
}

\author{
W. Köller and W. F. Wilcox, Department of Plant Pathology, Cornell University, New York State Agricultural Ex- \\ periment Station, Geneva 14456; and A. L. Jones, Department of Botany and Plant Pathology, Michigan State Uni- \\ versity, East Lansing 48824
}

\begin{abstract}
Köller, W., Wilcox, W. F., and Jones, A. L. 1999. Quantification, persistence, and status of dodine resistance in New York and Michigan orchard populations of Venturia inaequalis. Plant Dis. 83:66-70.

Isolates of Venturia inaequalis were sampled from apple orchards during 1990 to 1996 and isolate sensitivities to dodine were determined by testing the relative growth (RG) of mycelial colonies at a discriminatory dose of $0.2 \mu \mathrm{g} \mathrm{ml}^{-1}$. Sensitivities were not significantly different for a wild-type population and several populations sampled from orchards never or rarely treated with dodine, and respective data were combined to provide a reference for baseline populations. The baseline sensitivity was compared with sensitivities determined for four orchards with evidence for practical dodine resistance. At these sites, increases of phenotype frequencies were most pronounced for isolates with RG values $>90$; they had increased from a baseline level of 0.9 to $>30 \%$ and, therefore, were rated dodine-resistant. For two orchards with confirmed cases of previous dodine resistance, frequencies of resistant isolates had declined to 11 and $14 \%$ after dodine use was discontinued for 13 and 4 years, respectively. Sensitivities had not returned to baseline levels, and indirect evidence suggested that practical dodine resistance could recur rapidly in response to resumed dodine usage. Monitoring of commercial orchards in New York and Michigan revealed that dodine sensitivities were not uniform throughout regions where dodine resistance was widespread in the late 1970s. Sensitivities ranged from baseline to dodine-resistant and appeared to reflect the dodine use history at particular sites. Because the history of dodine use is not always known to growers, applications of dodine remain risky when accurate historical records are not available.
\end{abstract}

Dodine was introduced in the late 1950 s as a highly active fungicide against the apple scab fungus Venturia inaequalis (Cooke) G. Wint. In addition to providing good protective activities, dodine also inhibits the production of conidia in visible lesions $(1,18)$. The antifungal activity of dodine in the control of apple diseases is largely restricted to $V$. inaequalis; therefore, the fungicide was extensively used in applegrowing regions of northeastern North America, where scab is the main fungal pathogen of economic significance $(3,5)$.

In 1968, the first failures of apple scab control with dodine were experienced in orchards of the western apple-growing region of New York, where dodine had been applied as the exclusive scab fungicide for more than 10 years $(3,6)$. Initial evidence indicated that the control failures

Corresponding author: W. Köller

E-mail:wk11@cornell.edu

This study was supported in part by the USDA (90-34103-539 and 94-37313-0678) and by the New York State Apple Research and Development Program.

Accepted for publication 5 October 1998.

Publication no. D-1998-1118-01R

(C) 1999 The American Phytopathological Society were caused by the development of dodine resistance (19). The original report was subsequently confirmed for New York $(4,20)$ and other regions of the United States and Canada (7,12,13,15,16,21). Resistance developed primarily where dodine was used in exclusive programs. Until 1974, no resistance had been reported from the eastern part of New York (Hudson Valley), where the need to control multiple pathogens had ordinarily restricted dodine use to not more than two early-season sprays (3).

In New York and Michigan, dodine was largely replaced by other scab-control fungicides in the 1970s $(3,5)$. Because regulatory restrictions and fungicide resistance has resulted in either the loss or restricted use of several important scab-control fungicides (6), there is renewed interest in dodine for apple scab control, and some growers returned to dodine for one or two applications per season, particularly when other fungicides were unavailable. In addition, the recent detection in a commercial orchard in Michigan of practical resistance of $V$. inaequalis to sterol demethylation inhibitors (DMIs; 11) indicates that intensive and exclusive use of DMIs should be avoided if the effectiveness of this important class of fungicides is to be maintained.

It is difficult for growers, extension personnel, and crop consultants to judge the potential risk of dodine resistance in a given orchard because most of the orchards identified as dodine-resistant 20 to 30 years ago have been replaced with new orchards, have changed ownership, or were abandoned, and because comprehensive spray records for others are not always available. Current data on the sensitivity of populations of $V$. inaequalis to dodine would be helpful in assessing how dodine might be used for apple-scab control.

The pattern of rather slowly declining dodine performance and the small sensitivity differences of $V$. inaequalis ascospores sampled from dodine-sensitive and -resistant orchards (3) share similarities with the gradual population shifts experienced with the DMIs $(8,11)$. Detection of this type of resistance development requires quantitative sensitivity tests, a statistically sufficient number of individual isolates tested, a definition of isolate sensitivities qualifying as resistant, and statistical methods for the comparison of orchard populations $(11,17)$. This task has not been accomplished for dodine. The present study was initiated to (i) provide monitoring procedures and data and (ii) assess the current status of dodine resistance in New York and Michigan.

\section{MATERIALS AND METHODS}

Sensitivity tests. Procedures for isolation and propagation of monoconidial isolates of $V$. inaequalis and sensitivity tests were as described previously for the DMIs $(9,17)$. In brief, diseased leaves were arbitrarily collected from several trees distributed throughout an orchard, mycelial colonies of conidial isolates were grown from one lesion per leaf, and isolate sensitivities were determined by measuring relative mycelial growth (RG) at a discriminatory dose of dodine close to the mean effective dose $\left(\mathrm{ED}_{50}\right)$ value of baseline populations. Mycelial colonies were grown for 6 weeks on potato dextrose agar (PDA) at $20^{\circ} \mathrm{C}$. $\mathrm{RG}$ was defined as the mean diameter of two to three colonies grown on PDA amended with a discriminatory dodine dose per mean colony diameters on unamended PDA $\times 100$. Sample sizes tested per orchard ranged from 30 to 50 leaves.

Reported $\mathrm{ED}_{50}$ values for typical dodinesensitive isolates of $V$. inaequalis were approximately $0.2 \mu \mathrm{g} \mathrm{ml}{ }^{-1}$ for germination of ascospores (4) and conidia (13) and the inhibition of mycelial growth (15). This 
concentration was, therefore, employed as a discriminatory dodine dose. $\mathrm{ED}_{50}$ values of representative isolates were calculated by regressing $R G$ values determined at dodine concentrations of $0.001,0.003$, $0.01,0.03,0.1,0.3$, and $1 \mu \mathrm{g} \mathrm{ml} l^{-1}$ against the $\log$ of the fungicide concentration. Dodine (analytical standard) was obtained from American Cyanamid, Princeton, New Jersey.

Baseline orchards. A group of isolated apple trees never treated with fungicides and spread over the Montezuma National Wildlife Refuge, Seneca County, New York was described previously as harboring a wild-type population of $V$. inaequalis $(10,11,17)$. Isolates tested for their dodine sensitivities were derived from conidia sampled in June 1990. Isolates tested in 1991 were obtained by discharging ascospores from overwintered leaves collected at the same site in October 1990.

The dodine sensitivity of the wild-type population was compared with population sensitivities of three orchards that had never or only sporadically been treated with dodine. One commercial orchard with expected dodine-resistance was located in eastern New York (Hudson Valley) and was sampled in June 1990. One orchard planted in 1978 was an experimental orchard at the New York State Agricultural Experiment Station, where dodine had rarely been tested. This orchard was sampled in June 1991. One orchard in Wayne County, New York, was planted 4 years prior to sampling in June 1991 and had never been treated with dodine. However, the owner expected dodine resistance, because the orchard was located in the vicinity of orchards that had shown dodine resistance in the 1970s. Diseased leaves collected from the orchards described above originated from unsprayed trees.

Sites with current evidence for dodine resistance. In one orchard in western New York, dodine was used in 1990 and 1991. The dodine-use history prior to 1986 was not known to the grower because of changing orchard ownership. Control levels achieved with dodine in 1990 were satisfactory, but four dodine applications in 1991 yielded commercially unsatisfactory control of scab. Diseased leaves for sensitivity tests were collected in June 1991 from trees treated with dodine.
The second sampling site was an orchard in eastern New York (Hudson Valley). Dodine had been applied from 1969 to 1983 , with intensive use from 1974 to 1977. Following poor performance, with resistance suspected as the cause, dodine use was discontinued from 1984 to 1990. Two applications of dodine in 1991 yielded commercially unsatisfactory control of apple scab. Diseased leaves for sensitivity tests were collected in June 1991 from dodine-treated trees.

A third site was a commercial orchard in Michigan. Dodine had been used intensively over several seasons prior to a severe control failure in 1990. Isolates for sensitivity tests were derived from cultures of single ascospores obtained by discharging ascospores from overwintered leaf litter collected in 1990.

A fourth site was located in the Lake Champlain region of New York. The orchard was 50 years old and had been treated with two early-season sprays for approximately 30 years. A severe failure of scab control was experienced in 1996. Diseased leaves were sampled from treated trees in July 1996.

Sites with cases of dodine resistance confirmed previously. The orchard in Michigan with dodine-resistant scab in 1991 was sampled again in June 1995, using lesions from primary infections on unsprayed trees as the source for test isolates. The orchard had not been treated with dodine since 1991.

Two orchards in Wayne County, New York, which had experienced severe control failures in 1977 due to confirmed dodine resistance, were sampled in June 1991. One of the orchards had been abandoned in 1986, the other remained in production. Dodine had not been used at either site for the previous 13 years.

Monitoring of commercial sites. Five commercial orchards in New York and three in Michigan were sampled in June 1991. The sites were chosen according to grower expectations regarding the status of dodine resistance. The orchards had either been treated with dodine with good control of scab reported by respective growers, or dodine use had been discontinued because growers suspected dodine resistance (Table 1).

Data analysis. Sensitivity data were analyzed as described previously (11).
Frequency distributions of RG values determined for individual orchard populations were compared with the nonparametric Kolmogorov-Smirnov test of SYSTAT (version 5.2, Systat, Inc., Evanston, IL). Categorical sensitivity data were compared according to the log linear model of SYSTAT (likelihood ratio Chi-square; version 5.2 , Systat, Inc.), with the number of isolates grouped into the categories "sensitive" and "resistant." The model evaluates the homogeneity of categorical sensitivity distributions among populations of $V$. inaequalis. Nonhomogeneity indicates differences in the distribution of sensitive and resistant isolates, with the level of confidence determined by both the differences of isolate counts in the two categories and the sample sizes employed in respective tests.

\section{RESULTS}

Sensitivities of baseline populations. Sensitivity distributions of $V$. inaequalis isolates were first determined for a wildtype population at the Montezuma Wildlife Refuge. Isolates tested originated from conidia $(n=49$; mean $\mathrm{RG}=44)$ and from ascospores $(n=49$; mean $\mathrm{RG}=40)$ sampled in 1990 and 1991, respectively. The mean RG values were not significantly different $(P=0.2)$ for the two sampling dates and spore types, and the data were combined to provide a sensitivity distribution for a wild-type population never exposed to fungicides. Three populations of $V$. inaequalis originating from orchards never or only sporadically treated with dodine had mean RG values of 37,38 , and 44. These mean sensitivities were not significantly different from the wild-type population $(P>0.15)$. Therefore, all isolate sensitivities were combined to provide a typical baseline distribution exhibiting a mean RG value of 41 . The dodine sensitivity distribution for these baseline isolates $(n=232)$ was unimodal but not symmetric (Fig. 1A). $\mathrm{ED}_{50}$ values determined for the most- and least-sensitive baseline isolates $\left(0.024\right.$ and $1.2 \mu \mathrm{g} \mathrm{ml}{ }^{-1}$, respectively) were separated by a factor of 50 . The mean baseline sensitivity $(\mathrm{RG}=41)$ corresponded to an $\mathrm{ED}_{50}$ value of $0.17 \mu \mathrm{g}$ $\mathrm{ml}^{-1}$.

Sensitivities of dodine-resistant populations. Dodine sensitivities were deter-

Table 1. Description of commercial orchards tested for dodine sensitivities of Venturia inaequalis populations

\begin{tabular}{llll}
\hline Site & \multicolumn{1}{c}{ Region } & \multicolumn{1}{c}{ Dodine history ${ }^{\mathbf{a}}$} & Grower expectation \\
\hline 1 & Eastern New York & 1 to 2 dodine applications for 20 years; good scab control & No resistance \\
2 & Eastern New York & 1 to 2 dodine applications for 20 years; good scab control & No resistance \\
3 & Western New York & 2 to 3 dodine applications for 10 years; good scab control & No resistance \\
4 & Western New York & Dodine history prior to 1980 unknown; 3 dodine applications per year & No resistance \\
& & from 1988 to 1990; satisfactory scab control & Resistance \\
5 & Eastern New York & Control failure with dodine in 1978. Dodine use was discontinued. & Resistance \\
6 & Michigan & Control failure with dodine in 1980. Dodine use was discontinued. & Resistance \\
7 & Michigan & Control failure with dodine in 1980. Dodine use was discontinued. & Resistance \\
8 & Michigan & Control failure with dodine in 1986. Dodine use was discontinued. & \\
\hline
\end{tabular}

${ }^{\text {a }}$ According to grower information. 
mined for populations sampled from two New York orchards where dodine gave unsatisfactory scab control in 1991. Both populations were significantly less sensitive than the baseline population $(P<$ $0.001)$. Mean dodine RG values determined for the two populations were 68 ( $n=$ $30)$ and $67(n=46)$, respectively. As these sensitivities were not different $(P=0.95)$, the data from the two sites were combined (Fig. 1B).

The sensitivity distribution of the population was bimodal, and isolates with $\mathrm{RG}=$ 70 had declined in frequencies in comparison to the baseline distribution (Fig. 1B). In contrast, isolates with RG > 90 had increased from $0.9 \%$ in the baseline population to $32 \%$. Isolates of the intermediate sensitivity range ( $\mathrm{RG}=71$ to 90$)$ had also increased over baseline frequencies, but changes were small in comparison (Fig. 1B).

Sensitivities were also determined for an orchard in Michigan (1991) and in New York (1996), where control failures were experienced following applications of dodine. The sensitivities determined for the two sites were not significantly different from each other when applying both statis-

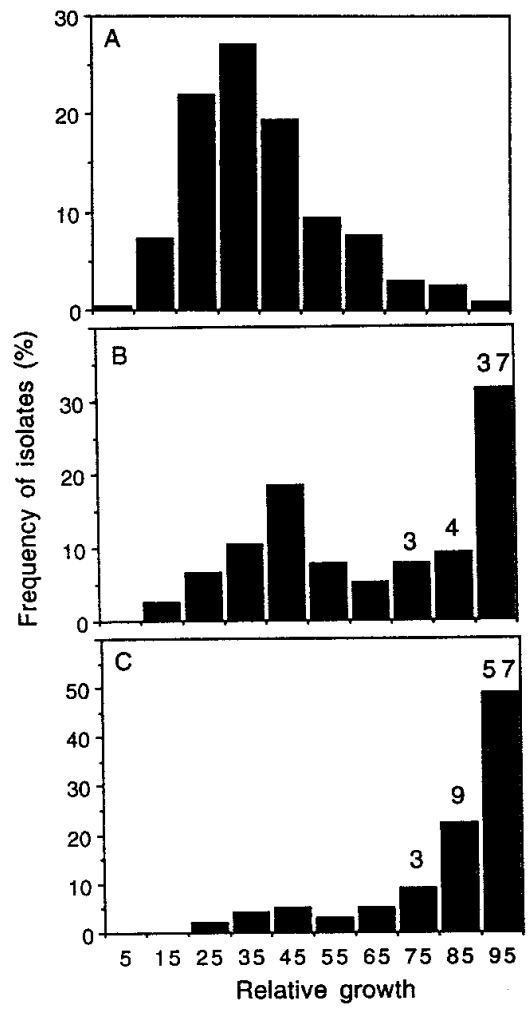

Fig. 1. Distribution of dodine sensitivities of Venturia inaequalis populations. (A) Baseline sensitivity distribution $(n=238)$; (B) population representing the threshold level of dodine resistance $(n=76)$; and $(\mathbf{C})$ population representing dodine resistance $(n=98)$. Numbers above bars in (B) and (C) are the factors of frequency increases from baseline levels for isolates testing with relative growth values of 71 to 100 . tical tests, the comparison of RG means ( $P$ $=0.11$ ), and isolate counts in the categories $\mathrm{RG}=70,71$ to 90 , and $>90(P=0.10)$. Therefore, the sensitivity data $(n=98)$ were combined to represent a second population resistant to dodine (Fig. 1C). Compared to the population with a lower level of resistance (Fig. 1B), frequencies of isolates with $\mathrm{RG}=70$ had declined further and those with RG > 90 had continued to increase. Frequency changes in the intermediate range of $R G=71$ to 90 were again small in comparison (Fig. 1C).

The dynamics of population shifts from baseline sensitivities (Fig. 1A) over low (Fig 1B) to high (Fig. 1C) levels of dodine resistance was consistent with a continuous selection of least-sensitive isolates already detected in baseline populations. Frequency increases in both resistant populations were most pronounced for isolates with RG > 90. This sensitivity was designated as dodine-resistant. The RG value of 90 separating sensitive and resistant isolates corresponded to an $\mathrm{ED}_{50}$ value of 1.0 $\mu \mathrm{g} \mathrm{ml} \mathrm{m}^{-1}$.

The baseline frequency of dodine-resistant isolates $(0.9 \% ; n=232)$ was significantly lower $(P<0.001)$ than respective frequencies in populations representing either a low $(32 \% ; n=76)$ or a high $(49 \%$; $n=98$ ) level of dodine resistance. With the sample sizes employed, respective frequencies were also significantly different $(P=0.02)$ for the two resistant populations. However, with smaller sample sizes ( $n=40$ to 50 ), which were used in the comparison of orchard sensitivities described below, the confidence of differentiating between a low and a high level of dodine resistance would decrease $(P=0.11$ to 0.07$)$. Therefore, the data of both resistant populations were combined to provide a single dodine-resistant reference population.

Persistence of dodine resistance. An orchard in Michigan (MI91) resistant to dodine in 1991 and part of the sensitivity distribution representing a high level of resistance (Fig. 1C) was retested in 1995 (MI95). Dodine use had been suspended for 4 years prior to sampling. The frequency of resistant isolates had declined to a level significantly lower than typical for resistant populations; however, it had not returned to a baseline level (Table 2). A similar pattern was observed for mean RG values determined for the sensitive population ( $\mathrm{RG} \leq 90)$, which describes both the group of isolates that had either declined $(\mathrm{RG}=70)$ or slightly increased $(\mathrm{RG}=71$ to 90) in frequencies during the course of selection (Fig. 1). Consistent with the high level of dodine resistance detected in 1991, the mean RG value was higher (MI91) than for the resistant reference population (Table 2) and had declined significantly $(P$ $<0.001)$ after dodine had not been used for 4 years (MI95). However, the mean RG value remained at a level typical for dodine-resistant rather than baseline populations (Table 2).

The dodine sensitivities found in the resistant Michigan orchard after dodine use had been suspended for 4 years were compared with a composite population derived from two orchards in Wayne County, New York. At these sites, control failures due to confirmed dodine resistance were experience in 1977 and dodine use had been discontinued for 13 years prior to sampling. There was no evidence of a difference between this New York population (Wayne) and the retested Michigan population (MI95) (Table 2). Both the frequencies of dodine-resistant isolates and the

Table 2. Dodine sensitivities of Venturia inaequalis populations in orchards with previously confirmed dodine resistance but no recent dodine use

\begin{tabular}{lcccccc}
\hline & \multicolumn{2}{c}{ Reference populations } & & \multicolumn{3}{c}{ Orchard sites } \\
\cline { 2 - 3 } \cline { 5 - 6 } & Baseline & Resistant $^{\mathbf{a}}$ & & MI91 $^{\mathbf{b}}$ & MI95 $^{\mathbf{b}}$ & Wayne $^{\mathbf{c}}$ \\
\hline$n$ & 232 & 174 & & 48 & 50 & 59 \\
$S^{\mathrm{d}}$ & 99.1 & 58.6 & & 50 & 86 & 89 \\
$R^{\mathrm{d}}$ & 0.9 & 41.4 & & 50 & 14 & 11 \\
$\mathrm{P}(\text { Baseline })^{\mathrm{e}}$ & $\ldots$ & $\ldots$ & & $<0.001$ & $<0.001$ & $<0.001$ \\
$\mathrm{P}(R)^{\mathrm{e}}$ & $\ldots$ & $\ldots$ & & 0.33 & $<0.001$ & $<0.001$ \\
${\text { Mean RG }(\mathrm{S})^{\mathrm{f}}}^{\mathrm{y}}$ & 41 & 61 & & 77 & 59 & 58 \\
$\mathrm{P}(\text { Baseline })^{\mathrm{g}}$ & $\ldots$ & $\ldots$ & & $<0.001$ & $<0.001$ & $<0.001$ \\
$\mathrm{P}(R)^{\mathrm{g}}$ & $\ldots$ & $\ldots$ & 0.001 & 0.15 & 0.20 \\
\hline
\end{tabular}

a Both resistant populations described in Figure 1 combined.

${ }^{b}$ Populations from a commercial orchard in Michigan with a control failure due to dodine resistance in 1990. The orchard was tested in 1991 (MI91) and again in 1995 (MI95), after dodine had not been used for 4 years.

Composite population from two sites in Wayne County, New York. Control failures due to dodine resistance were confirmed in 1977, and dodine had not been used since 1978. The orchards were sampled in 1991.

${ }^{\mathrm{d}}$ Frequencies of isolates $(\%)$ in each category. $S=$ sensitive, relative growth $(\mathrm{RG})=90$; and $R=$ resistant,. $\mathrm{RG}>90$.

${ }^{\text {e }}$ Comparison of counts of isolates classified $S$ or $R$ in baseline and resistant populations with respective counts determined for the populations retrieved from specified orchard sites (log-linear model).

${ }^{\mathrm{f}}$ Mean RG values of $S(\mathrm{RG}=90)$ isolates.

g Comparison of mean RG values of $S$ isolates (Kolmogorov-Smirnov test). 
mean RG values of sensitive isolates were not different $(P>0.5)$ for the two populations.

Monitoring of dodine resistance in commercial orchards. The sensitivities of $V$. inaequalis populations were determined for eight commercial orchards (Table 1) and the results were compared with the expectations of respective growers regarding the status of dodine resistance at their sites. In three New York orchards expected to be sensitive, dodine use had been restricted to one to three early-season applications (orchards 1, 2, and 3). Frequencies of resistant isolates were either baseline or significantly lower than typical for resistant populations; mean RG values of sensitive isolates were not different from the baseline reference (Table 3). For a fourth site assumed to be dodine sensitive (orchard 4), both monitoring parameters indicated a significant shift of isolate sensitivities toward dodine resistance (Table $3)$. However, the level of resistance did not yet diagnose practical dodine resistance (Table 3). Overall, the grower expectations of dodine-sensitive sites were confirmed by our results and were consistent with good scab control with programs utilizing the fungicide (Table 1).

The population in one New York orchard (orchard 5), with a scab-control failure attributed to dodine resistance in 1978 and not treated with dodine since, was shown to exhibit baseline sensitivities (Table 3). Two other populations (orchards 6 and 7) assumed to be dodine-resistant had levels of resistance falling between the baseline and dodine-resistant reference populations (Table 3). In contrast, the grower expectation of resistance was fully confirmed for orchard 8 (Table 3). Here, both the frequency of resistant isolates and the mean RG of sensitive isolates could not be distinguished from reference values indicating dodine resistance.

\section{DISCUSSION}

In this study, we have evaluated the status of dodine sensitivities of $V$. inae- qualis populations in New York and Michigan orchards employing a monitoring approach developed previously for the DMI fungicides $(9,11,17)$. As was observed with the DMIs, the distribution of dodine sensitivities determined for baseline isolates was broad and unimodal, and isolates considerably less sensitive than the baseline mean had increased in frequencies at sites with practical resistance to dodine. As described for the DMIs before (11) and as expected for broad sensitivity distributions, increases of phenotype frequencies were dependent on their sensitivities relative to the baseline mean. Most pronounced increases were observed for isolates with $\mathrm{RG}>90\left(\mathrm{ED}_{50}>1 \mu \mathrm{g} \mathrm{ml}^{-1}\right)$; therefore, these isolates were defined as dodine resistant.

The classification of isolates into the categories of dodine sensitive and dodine resistant allowed the comparison of orchard populations by log linear analysis of categorical data, as described for the DMI fungicides (11). In order to also account for sensitivity changes within the dodine-sensitive part of the population $(\mathrm{RG}=90)$, which were apparent during the course of resistance development (Fig. 1), the mean RG value of sensitive isolates was utilized as a second monitoring parameter for orchard comparisons.

With the monitoring tools and data in hand, three questions were addressed: (i) how stable is dodine resistance after dodine use was discontinued for several years, (ii) how uniform is dodine resistance in regions with widespread resistance problems in the 1970s, and (iii) how do grower perceptions regarding dodine resistance at a particular site compare with monitoring data?

Retesting of a dodine-resistant Michigan orchard after 4 years of suspended dodine use and data obtained for two sites in New York with previously confirmed resistance but no dodine usage for 13 years revealed that levels of resistance had declined significantly. Regardless of this decline, however, both populations remained less sensi- tive than baseline. A similar level of resistance higher than baseline but below practical resistance was also detected for two of the four commercial sites, where dodine had not been used for several years because growers suspected resistance. Only one of these orchards had retained a prohibitively high level of resistance.

The practical impact of declining levels of dodine resistance, which might be explained by the multigenic nature of dodine resistance reported for $V$. inaequalis $(2,14,21)$, was not directly investigated in our study. However, indirect evidence suggests that practical resistance can recur rapidly following resumption of dodine usage. The two orchards harboring a low yet prohibitive frequency of resistant isolates (Fig. 1B) provide an example. The owner of one of the orchards was unaware of the dodine history prior to 1986. Although dodine had not been used for at least 5 years, a total of eight dodine applications led to an outbreak of practical dodine resistance. Presumably, this orchard had experienced problems with dodine resistance in the past and, although resistance levels might have declined in the interim, practical resistance recurred within two seasons. The second orchard had a history of intensive dodine usage and declining dodine performance. Scab control achieved with two dodine applications was unsatisfactory and frequencies of dodine-resistant isolates were high, even after the fungicide had not been applied for 6 years.

The orchards evaluated in this study were located in regions with widespread cases of dodine resistance in the 1970s and early 1980s. Our monitoring data demonstrated that the distribution of dodine resistance was not uniform within these regions. For example, the sensitivities of two commercial orchards, where dodine had never or rarely been used, could not be distinguished from a wild-type population. Sensitivities at or close to baseline were also detected for three commercial orchards where a limited number of dodine

Table 3. Dodine sensitivities of Venturia inaequalis populations in commercial orchards of New York and Michigan

\begin{tabular}{|c|c|c|c|c|c|c|c|c|c|c|}
\hline & \multicolumn{2}{|c|}{ Reference populations } & \multicolumn{8}{|c|}{ Orchard sites (grower expectations) ${ }^{\mathrm{a}}$} \\
\hline & Baseline & Resistant $^{\mathbf{b}}$ & $1(-)$ & $2(-)$ & $3(-)$ & $4(-)$ & $5(+)$ & $6(+)$ & $7(+)$ & $8(+)$ \\
\hline$n$ & 232 & 174 & 48 & 48 & 50 & 49 & 46 & 47 & 41 & 40 \\
\hline$S^{\mathrm{c}}$ & 99.1 & 58.6 & 98 & 92 & 90 & 78 & 100 & 91 & 76 & 67 \\
\hline$R^{\mathrm{c}}$ & 0.9 & 41.4 & 2 & 8 & 10 & 22 & 0 & 9 & 24 & 33 \\
\hline$P(\text { Baseline })^{\mathrm{d}}$ & $\ldots$ & $\ldots$ & 0.43 & $<0.01$ & $<0.01$ & $<0.01$ & 0.73 & $<0.01$ & $<0.01$ & $<0.01$ \\
\hline$P(R)^{\mathrm{d}}$ & $\ldots$ & $\ldots$ & $<0.01$ & $<0.01$ & $<0.01$ & 0.01 & $<0.01$ & $<0.01$ & 0.04 & 0.30 \\
\hline Mean RG $(S)^{\mathrm{e}}$ & 40 & 61 & 41 & 41 & 40 & 51 & 42 & 50 & 56 & 65 \\
\hline$P(\text { Baseline })^{f}$ & $\ldots$ & $\ldots$ & 0.67 & 0.84 & 0.93 & $<0.01$ & 0.67 & $<0.01$ & $<0.01$ & $<0.01$ \\
\hline$P(R)^{\mathrm{f}}$ & $\ldots$ & $\ldots$ & $<0.01$ & $<0.01$ & $<0.01$ & $<0.01$ & $<0.01$ & $<0.01$ & 0.03 & 0.25 \\
\hline \multirow{2}{*}{\multicolumn{11}{|c|}{$\begin{array}{l}\text { a Orchard sites and dodine use histories are described in Table } 1 ;(-)=\text { no expectation of resistance and }(+)=\text { growers suspected resistance. } \\
\text { b Both resistant populations described in Figure } 1 \text { combined }\end{array}$}} \\
\hline & & & & & & & & & & \\
\hline \multirow{3}{*}{\multicolumn{11}{|c|}{ c Frequencies of isolates (\%) in each category. $S=$ sensitive, relative growth $(\mathrm{RG})=90$; and $R=$ resistant, $\mathrm{RG}>90$. }} \\
\hline & & & & & & & & & & \\
\hline & & & & & & & & & & \\
\hline . & $n$ RG & & & & & & & & & \\
\hline
\end{tabular}


sprays per season had provided good control of scab for 10 to 20 years, and for an orchard suspected to be resistant because dodine had provided poor control of scab 12 years prior to sampling.

Our results indicate that levels of dodine resistance more closely reflect the dodine history of a particular site than the previous history of resistance within a region. For example, three orchards that had received a total of approximately 30 dodine applications over a period of 10 to 20 years remained dodine sensitive The result confirmed that, in orchards with fewer dodine applications per season, the commercial utility of dodine was expanded over a longer period of years. However, in another orchard, two applications per season expanded over more than 30 years and corresponding to more than 60 applications had led to a control failure and a high level of resistance. The total number of dodine applications this orchard received compares well with the reported history of previous dodine resistance. In New York, resistance emerged after scab had been managed with a total of 70 to 90 dodine applications, corresponding to the exclusive use of dodine for 12 to 15 years (3).

Although the total number of dodine applications at a particular site might serve as guidance for the status of dodine resistance, with 60 to 70 treatments representing a potential upper limit, our survey revealed that grower expectations were not always a reliable source for management decisions. The establishment of baseline and resistant reference populations (Fig. 1) and the survey of selected orchards (Table 3) involved a total of 14 growers. Six of these growers expected dodine resistance; our monitoring results ranked three of these orchards as fully sensitive. Eight growers had used dodine because they expected their orchards to be dodine sensitive. Expectations were only confirmed for three of the eight orchards; five orchards were approaching or matching a level of practical resistance. The owners of the latter orchards were either not aware of the previ- ous history of dodine resistance because of changing ownership, or they had used dodine until it failed to control the disease.

The survey of orchards described above was not random and our conclusions are, therefore, preliminary. Regardless of these limitations, our results do not warrant the unlimited reintroduction of dodine as a single compound for the control of apple scab, in particular where precise records of previous dodine usage are not available. However, dodine sensitivities were not uniform throughout regions and, with antiresistance strategies in place, the fungicide might continue to serve as a valuable tool in scab control. This question and a more random survey of orchard populations are under investigation. Regardless of the open questions to be resolved, the monitoring approach and the data provided in this study should apply to regions of dodine usage other than New York and Michigan.

\section{ACKNOWLEDGMENTS}

We thank M. Szkolnik for his help in identifying orchards with documented cases of previous dodine resistance in Wayne County, New York.

\section{LITERATURE CITED}

1. Albert, J. J., and Lewis, F. H. 1962. Effect of repeated applications of dodine and of captan on apple scab foliage lesions. Plant Dis. Rep. 46:163-167.

2. Georgopoulos, S. G. 1995. The genetics of fungicide resistance. Pages 39-52 in: Modern Selective Fungicides, 2nd edition. H. Lyr, ed. Gustav Fischer Verlag, Jena.

3. Gilpatrick, J. D. 1982. Case study 2: Venturia on pome fruits and Monilinia on stone fruits. Pages 195-206 in: Fungicide Resistance in Crop Protection. J. Dekker and S. G. Georgopoulos, eds. Centre for Agricultural Publishing and Documentation, Wageningen.

4. Gilpatrick, J. D., and Blowers, D. R. 1974. Ascospore tolerance to dodine in relation to orchard control of apple scab. Phytopathology 64:649-652.

5. Jones, A. L. 1981. Fungicide resistance: Past experience with benomyl and dodine and future concerns with sterol inhibitors. Plant Dis. 65:990-992.

6. Jones, A. L. 1995. A stewardship program for using fungicides and antibiotics in apple disease management programs. Plant Dis. 79:427-432.
7. Jones, A. L., and Walker, R. J. 1976. Tolerance of Venturia inaequalis to dodine and benzimidazole fungicides in Michigan. Plant Dis. Rep. 60:40-42.

8. Köller, W. 1990. Fungicide resistance in plant pathogens. Pages 679-720 in: CRC Handbook of Pest Management in Agriculture, 2nd ed., Vol. 2. D. Pimentel, ed. CRC Press, Boca Raton, FL.

9. Köller, W., Parker, D. M., and Reynolds, K. L. 1991. Baseline sensitivities of Venturia inaequalis to sterol demethylation inhibitors. Plant Dis. 75:726-728.

10. Köller, W., Smith, F. D., Reynolds, K. L., Wilcox, W. F., and Burr, J. A. 1995. Seasonal changes of sensitivities to sterol demethylation inhibitors in Venturia inaequalis populations. Mycol. Res. 99:689-692.

11. Köller, W., Wilcox, W. F., Barnard, J., Jones, A. L., and Braun, P. G. 1997. Detection and quantification of resistance of Venturia inaequalis populations to sterol demethylation inhibitors. Phytopathology 87:184-190.

12. MacNeill, B. H., and Schooley, J. 1973. The development of tolerance to dodine in Venturia inaequalis. Can. J. Bot. 51:379-382.

13. McKay, M. C. R., and MacNeill, B. H. 1979. Spectrum of sensitivity to dodine in field populations of $V$. inaequalis. Can. J. Plant Pathol. 1:76-78.

14. Polach, F. J. 1973. Genetic control of dodine tolerance in Venturia inaequalis. Phytopathology 63:1189-1190.

15. Ross, R. G., and Newbery, R. J. 1977. Tolerance of Venturia inaequalis to dodine in Nova Scotia. Can. Plant Dis. Surv. 57:57-60.

16. Sholberg, P. L., Yorston, J. M., and Warnock, D. 1989. Resistance of Venturia inaequalis to benomyl and dodine in British Columbia, Canada. Plant Dis. 73:667-669.

17. Smith, F. D., Parker, D. M., and Köller, W. 1991. Sensitivity distribution of Venturia inaequalis to flusilazole: baseline sensitivity and implications for resistance monitoring. Phytopathology 81:392-396.

18. Szkolnik, M. 1981. Physical modes of action of sterol-inhibiting fungicides against apple diseases. Plant Dis. 65:981-985.

19. Szkolnik, M., and Gilpatrick, J. D. 1969. Apparent resistance of Venturia inaequalis to dodine in New York apple orchards. Plant Dis. Rep. 53:861-864.

20. Szkolnik, M., and Gilpatrick, J. D. 1973. Tolerance of Venturia inaequalis to dodine in relation to the history of dodine usage in the orchard. Plant Dis. Rep. 57: 817-821.

21. Yoder, K. S., and Klos, E. J. 1976. Tolerance to dodine in Venturia inaequalis. Phytopathology 66:918-923. 